te, por lo que sería de interés conocer más detalles sobre los problemas, estrategias y soluciones adoptados en un trabajo de campo tan ambicioso y complejo. Por otro lado, dichas aclaraciones podrían aportar mayor credibilidad a los resultados, aclarando ciertas dudas que plantea el diseño de investigación. Por ejemplo, no queda clara la forma de selección y acceso a los entrevistados, lo que es clave para interpretar, por ejemplo, la representatividad del bajo porcentaje observado de casos de exclusión residencial extrema. También plantea dudas acerca de la representatividad de los resultados la falta de información sobre la vinculación territorial de las observaciones, es decir, la distribución espacial de las cuotas (tipos de ciudad, barrios, etc.). Este aspecto cobra particular importancia al analizar aspectos como la percepción del nivel social del barrio o el nivel de concentración, ya que dichas observaciones tienen una alta vinculación con el territorio concreto donde las entrevistas han sido realizadas.

Albert TERRONES

\section{Lorenzo Cachón}

\section{Bases sociales de los sucesos de Elche: Crisis industrial, inmigración y xenofobia}

(Madrid, Ministerio de Trabajo y Asuntos Sociales, 2006)

La internacionalización de la economía y la eliminación de los aranceles en pro de la libre cir- culación de las mercancías son procesos macroeconómicos que, a menor escala, cristalizan bajo unas coordenadas sociales, étnicas y políticas específicas. Los sucesos de Elche, al ser abordados en perspectiva, nos obligan a levantar la vista más allá de los límites de una ciudad de apenas 300.000 habitantes, de la producción del calzado y, en última instancia, más allá del incendio de dos naves de calzado propiedad de un ciudadano chino en un polígono industrial en septiembre de 2004. En este aspecto, el estudio de las Bases sociales de los sucesos de Elche documenta y analiza esas coordenadas sociales, étnicas y políticas concretas. Ya el subtítulo del libro: Crisis industrial, inmigración y xenofobia, nos da pistas sobre los vectores que vertebran el análisis.

El trabajo de Cachón se desarrolla desde un planteamiento estructuralista clásico: proyección histórica, estructura económica y social. Una vez dibujado el escenario, se relatan los sucesos propiamente dichos y se exponen los discursos y acciones de los actores implicados, que, a la luz del análisis previo, aparecen como la crónica de una muerte anunciada (mirando hacia atrás) o como síntoma preocupante (si el enfoque es de futuro).

En un sentido dramático (tanto teatral como valorativo), el escenario de partida de los sucesos de Elche se configura desde los orígenes de la fabricación de calzado en el Levante español, iniciada a finales del siglo XIX a partir de la elaboración de alpargatas y, posteriormente, de calzado de piel. Un sector productivo con una alta concentración espacial, poco tecnificado, basada su competitividad en unos costes salariales bajos y con una escasa cualificación. 
Cachón, apoyándose en distintos estudios específicos sobre el sector y sobre la zona de Elche, identifica un conjunto de rasgos estructurales que han configurando la estructura productiva y ocupacional de la industria del calzado desde sus inicios. El distrito industrial del calzado se caracterizaría, además de por los aspectos señalados, por otro de vital importancia: la economía sumergida.

La adaptación de la industria del calzado a la crisis que se inicia en los setenta por la caída de las exportaciones, y que se agrava a lo largo de los ochenta en relación a la inserción de España en las Comunidades Europeas, se ha concretado en distintas estrategias. Como rasgo común a todas ellas se identifica, en primer lugar, el énfasis en la reducción de los costes salariales y, en el segundo, con una política defensiva que se ha centrado en cuatro mecanismos: la subcontratación concatenada, el trabajo a domicilio, la deslocalización de la producción y la economía sumergida como eje transversal («centrifugación de los productos y los procesos»).

Si el recurso a la economía informal en un primer momento pudo ser una vía de «consolidación» del sector, en los últimos años este cariz defensivo le ha otorgado una posición estructural. Un modelo productivo con estas bases no ofrece una salida esperanzadora para el sector no sólo a nivel económico, sino social, ya que implica la precarización de las condiciones laborales de los trabajadores del sector. Es una estrategia a corto plazo que es pan para hoy $y$ hambre para mañana.

Los efectos de estas transformaciones del modelo productivo de la industria del calzado se complejizan al ponerlo en relación con el actual ciclo migratorio que vive España y la problematización política de la nueva inmigración.

La economía sumergida no sólo ha favorecido el abaratamiento de los costes salariales, sino que opera como efecto llamada para la inmigración irregular, al tiempo que los trabajadores inmigrantes contribuyen al sostenimiento de una competitividad basada en el dumping social. La falta de futuro del sector y la precarización de las condiciones laborales tensan las relaciones entre los trabajadores autóctonos e inmigrados y catalizan la competición real que se produce en el mercado de trabajo secundario. Éste es el caldo de cultivo para el arraigo y expresión de discursos racistas renovados que desembocan en la búsqueda de chivos expiatorios entre colectivos que no son sino actores secundarios de un escenario ya prefigurado.

Así pues, nos encontramos con un sector productivo clave para un volumen importante de trabajadores, un sector en el que las prácticas irregulares se han generalizado, que no ha articulado eficazmente los mecanismos económicos y organizativos para poder competir en calidad, marca, diseño o imagen, y que lidia en un campo (bajos salarios) en el que potencias emergentes como China llevan mucho terreno adelantado. La estrategia de supervivencia por la que se opta no sólo no mejora el futuro, sino que lo compromete (en tanto que la calidad decae, no se fomenta la cualificación de la mano de obra), y ante la visión de la crisis rompe por el eslabón más débil: los comerciantes chinos, por un lado, y las condiciones de los puestos de trabajo que padecen especialmente las trabajadoras autóctonas y los trabajadores inmi- 
grantes irregulares, estos últimos especialmente marcados por las tres $P$, en palabras de Cachón: «los más penosos, los más peligrosos y los más precarios».

Los sucesos de Elche, a partir de este estudio, no serían especialmente sorprendentes; recuerdan al viejo dicho que reza «entre todos lo matamos y él solo se murió». El reparto de responsabilidades va más allá de los instigadores y autores materiales del incendio. Ya se insinúa desde el comienzo: las instituciones políticas tienen un papel central como catalizadores de estrategias comunes en los distritos industriales. Ya desde las primeras páginas se señala la ambigüedad de su actuación. Por otra parte, podría decirse que el empresariado autóctono del calzado ha hecho una apuesta estratégica y la ha perdido. La paradoja, tampoco sorprendente, es que las supuestas malas prácticas, la competencia desleal de la importación, son demasiado conocidas entre los propios productores. En cualquier caso, el reparto de responsabilidades alude a la necesidad de desplegar los mecanismos institucionales, políticos y económicos que aborden de cara al futuro la raíz estructural del conflicto, más allá del caso concreto de Elche.

El autor se preocupa por señalar las medidas en materia de política económica o la creación de espacios para abordar las raíces de la crisis del sector que se han propiciado con urgencia tras los incendios. Asimismo, hace una crónica escrupulosa de los acontecimientos y también de las manifestaciones de rechazo a lo sucedido por parte de los habitantes de Elche. Es importante señalar estos aspectos en tanto que nos permiten diferenciar el desarrollo de los acontecimientos de Elche de brotes xenófobos como los registrados en El Ejido (2000), Can Anglada (Terrassa, 1999), Níjar (Almería, 1999), Lepe (Huelva, 1999), etc.

Lo especialmente destacable del estudio de Cachón es que retrata las consecuencias de la aplicación o inhibición en materia de política económica. De aquí se derivan dos cuestiones fundamentales que quizá no estarían suficientemente abordadas en el estudio: ¿qué horizonte de posibilidades tiene el sector del calzado en el marco de la política económica europea? ¿Qué papel podría jugar la acción colectiva de los trabajadores (autóctonos e inmigrantes) en el futuro del sector?

La crisis del modelo productivo español, y en concreto del modelo productivo del calzado, no es una cuestión ajena a la división regional del trabajo y al fomento del sector servicios o de la industria del ocio en nuestro país, y especialmente en el Levante (i.e., Marina D'Or, Terra Mítica). La precarización de las condiciones laborales y la competitividad basada en el bajo coste de la mano de obra no son una cuestión aislada aplicable a este sector, si bien en él adquiere dimensiones especialmente graves. La pregunta sería: ¿la ineficaz o tardía intervención de las Administraciones públicas es producto de una falta de visión política o podría ser un síntoma de lo contrario?

Sin duda, estas preguntas no nos la podríamos plantear seriamente sin haber contado previamente con la cuidadosa labor documental, tanto teórica como recopilatoria de datos empíricos, que compone este libro. Como estudio exhaustivo que es, el análisis de Cachón no 
nos permite una lectura maniquea de la situación. La diversidad y la complejidad de los intereses, actores, estrategias y ámbito de actuación nos conducen a un escenario muy delicado tanto para el empresariado autóctono como para la población trabajadora, así como para el desarrollo social de la zona. Igual que al inicio, este escenario microscópico que se retrata en Elche, al ampliarse, nos remite a un modelo de producción con consecuencias económicas y político-sociales a escala regional europea e internacional.

Isabel BENÍTEZ ROMERO

\section{Carlota Solé (dir.)}

Inmigración comunitaria: ¿discriminación inversa?

(Barcelona, Anthropos, 2006)

Hablar de inmigración comunitaria implica hablar de migraciones de diverso origen y carácter, tanto cualitativo como cuantitativo. En un marco de libre circulación de personas en la Unión Europea relativamente asentado, es necesario abordar el estudio de estas migraciones dando cuenta de su cuantía y complejidad $y$, en su caso, desplazar las imágenes preconcebidas acerca de la inmigración de personas inactivas procedentes de la Unión Europea.

La inmigración comunitaria ha registrado un notable incremento a lo largo de los años ochenta y, a día de hoy, representa el 27\% del total de la inmigración que recibe España. Por su actual peso estadístico y por las nuevas variables de complejidad que plantea la ampliación de la Unión Europea a 27 miembros, se hacían precisas unas coordenadas generales sobre la inmigración comunitaria. En este sentido, la última publicación GEDIME ofrece una mirada más detallada en lo tocante a dos cuestiones centrales: las personas mayores jubiladas y las pautas de movilidad y de inserción laboral del colectivo de trabajadores y trabajadoras inmigrantes procedentes del espacio europeo ampliado.

El libro parte de una radiografía cuantitativa de la complejidad que las fuentes estadísticas imponen al estudio de este tipo de migración, al cual se le supone una mayor fiabilidad en sus registros, no siempre tan exhaustivos y coherentes como podría esperarse. En la primera parte se centra en la población jubilada afincada en España. Así, las nacionalidades comunitarias (de la Europa de los 15) más representadas en España serían la alemana y la inglesa.

Tradicionalmente, se ha relacionado a las personas mayores jubiladas e instaladas en España con una imagen idílica de opulencia de recursos. Las conclusiones de este estudio, empero, por un lado, ilustran que entre los jubilados comunitarios instalados en España también se registran desigualdades por razón de clase. Y, por otro, que estas desigualdades operan dentro de un marco de colisión de tres modelos de Estados de Bienestar europeo distintos y que proveen diferencialmente a sus ciudadanos, dentro de la clasificación propuesta por Esping-Andersen en Los tres mundos del Estado del bienestar. 